\title{
Schedule-induced drinking facilitates schedule-controlled feeding
}

\author{
J. D. KEEHN and ROSA RIUSECH \\ York University, Downsview, Ontario M3J 2R7, Canada
}

\begin{abstract}
Four food-deprived rats barpressed with food reinforcement on a 1-min fixed-interval schedule in 7-h sessions with water either present or absent. They all became polydipsic, drinking after many pellets early in sessions but after fewer pellets later in sessions. Pellets were secured at near maximum rates for about $3 \mathrm{~h}$. Thereafter, the three heaviest drinkers obtained more food with water than without it. The results indicate that schedule-induced drinking does not continue indefinitely and that it can be adaptive with regard to feeding.
\end{abstract}

Rats switch between eating and drinking apparently at random when food and water are freely available together (Keehn \& Colotla, 1970; Premack, 1965), but if water is free and food pellets are scheduled intermittently, then occasions and durations of drinks are predictable (Keehn \& Colotla, 1970). At interpellet intervals between about $15 \mathrm{sec}$ and $2 \mathrm{~min}$, a bout of drinking begins after almost every pellet delivery and lasts for a time that varies directly with the interpellet interval (Colotla, Keehn, \& Gardner, 1970; Hawkins, Schrot, Githens, \& Everett, 1972). Such eat-drink sequences of behavior do not terminate when normal water intakes are attained; Falk (1961) showed that in $3.17-\mathrm{h}$ sessions, with food pellets scheduled once per minute on the average, water consumption reaches polydipsic levels. Falk (1961) and most subsequent investigators have stressed the excessiveness of schedule-induced drinking, but have not described the distribution of eating and drinking over long periods of time. Such information was gathered in the present study, which also compared rates of barpressing and eating with and without water available.

\section{METHOD}

\section{Subjects}

Four 3-month-old experimentally naive male albino rats of the Wistar strain supplied by Woodlyn Farms, Guelph, Ontario, were maintained at $80 \%$ of their free-feeding weights in individual home cages. Water was available at all times.

Two standard $11.5 \times 9.5 \times 7.5 \mathrm{in} .(29 \times 23.5 \times 19 \mathrm{~cm})$ Grason-Stadler two-bar rat chambers (Type E3125 B) with pellet magazines that delivered $45-\mathrm{mg}$ Noyes rat pellets were the experimental spaces. In each box, the lever beside the door was removed and its housing covered with a metal plate mounted flush with the wall. A force of $0.19 \mathrm{~N}(20 \mathrm{~g})$ on the remaining bar activated relay scheduling and recording equipment in an adjoining room.

When water was to be available, a water bottle was attached to each chamber door such that the outlet tube was 2 in. $(5 \mathrm{~cm})$ above floor level and $7 \mathrm{in} .(18 \mathrm{~cm})$ from the food magazine. Licks on these tubes were counted and recorded on Gerbrands
}

cumulative recorders via Grason-Stadler drinkometers. Numbers of barpresses, licks, and reinforcers were displayed on printout counters at the end of each hour. Volume of water consumed per session was measured on sessions when water was available.

\section{Procedure}

The animals were trained to barpress for food pellets and then given two 1-h sessions in which every barpress was reinforced, five 1-h sessions with reinforcement scheduled at fixed 30-sec intervals, with water available on the last two of these, and two $1 / 2-h$ sessions with water available and reinforcement scheduled at fixed 60 -sec intervals. Then, subjects received seven "wet" and seven "dry" sessions, each $7 \mathrm{~h}$ long. On wet sessions, the water bottle was in place; on dry sessions, the bottle was removed. For Subjects 1 and 3, wet and dry sessions occurred in the order WDWDDDWDWWDWDW; the opposite order occurred for Subjects 2 and 4 . Animals normally received two training sessions per week with a rest day in between.

On two occasions 1 week apart before training commenced, water intakes, in 7-h periods when the subjects had free access to 420 reinforcer pellets in their home cages, were measured. All subjects consumed all the pellets on these occasions within the $7 \mathrm{~h}$.

\section{RESULTS}

We present first the overall amounts of fluid consumed, then the distribution of drinks over time, and then the relationships between barpressing, eating, and drinking.

The amounts of water drunk by each animal in each of the seven wet sessions appear in Table 1 along with the control intakes measured over $7 \mathrm{~h}$ in home cages at the same time of day with the same amount and kind of food available as in the experimental sessions. Water consumptions in the test chamber, when food pellets were scheduled once per minute, ranged from almost three times to over four times control intake levels when food pellets were presented all at once. The animals can be described as polydipsic, but fluid intakes were less than double those reported by Falk (1961), who used sessions less than half as long. The possibility that drinking was not evenly distributed throughout the 7-h sessions is confirmed by Figure 1, which displays 
Table 1

Water Intakes (in Milliliters) per 7-h Session

\begin{tabular}{|c|c|c|c|c|c|c|c|c|c|}
\hline \multirow[b]{2}{*}{ Subject } & \multicolumn{7}{|c|}{ Session } & \multirow[b]{2}{*}{ Mean } & \multirow[b]{2}{*}{ Control } \\
\hline & 1 & 2 & 3 & 4 & 5 & 6 & 7 & & \\
\hline 1 & 65 & 52 & 42 & 57 & 50 & 47 & 81 & 56.3 & 20.5 \\
\hline 2 & 133 & 167 & 110 & 192 & 155 & 118 & 136 & 144.4 & 30.0 \\
\hline 3 & & 64 & 101 & 55 & 115 & 85 & 95 & 85.8 & 23.5 \\
\hline 4 & 69 & 67 & 65 & 83 & 54 & 51 & 74 & 66.1 & 23.5 \\
\hline Mean & 89.0 & 87.5 & 79.5 & 96.7 & 93.5 & 75.2 & 96.5 & 88.1 & 24.4 \\
\hline
\end{tabular}

Note-Control intakes are means of two $7-h$ preexperimental control sessions with 420 pellets placed in the chamber at the start of each period.

Table 2

Mean Responses and Reinforcers per Hour Under Wet and Dry Conditions

\begin{tabular}{|c|c|c|c|c|c|c|c|c|}
\hline & \multicolumn{2}{|c|}{ Pellets/Hour } & \multicolumn{2}{|c|}{ Presses/Hour } & \multicolumn{2}{|c|}{ Presses/Pellet } & \multicolumn{2}{|c|}{ Mean Weight (grams) } \\
\hline & Dry & Wet & Dry & Wet & Dry & Wet & Dry & Wet \\
\hline Rat 1 & 49.2 & 47.1 & 518.8 & 477.4 & 10.5 & 10.1 & 294.8 & 290.5 \\
\hline Rat 2 & 43.2 & 53.0 & 384.5 & 474.4 & 8.9 & 8.9 & 299.4 & 298.5 \\
\hline Rat 3 & 41.5 & 47.6 & 749.0 & 858.0 & 18.0 & 18.0 & 348.3 & 348.1 \\
\hline Rat 4 & 48.3 & 53.7 & 494.8 & 643.2 & 10.2 & 11.9 & 314.3 & 314.0 \\
\hline Mean & 45.5 & 50.3 & 536.8 & 613.2 & 11.9 & 12.2 & 314.2 & 312.8 \\
\hline
\end{tabular}

licks per hour averaged over the last six wet sessions for each animal. In all animals, licking declined fairly steadily from Hour 1 to Hour 5. The licks increased for the final $2 \mathrm{~h}$ except in the case of Subject 4.

Table 2 reports barpresses and reinforcers per hour averaged separately over the wet and dry sessions, and also shows mean body weights at the beginning of each type of session and the mean

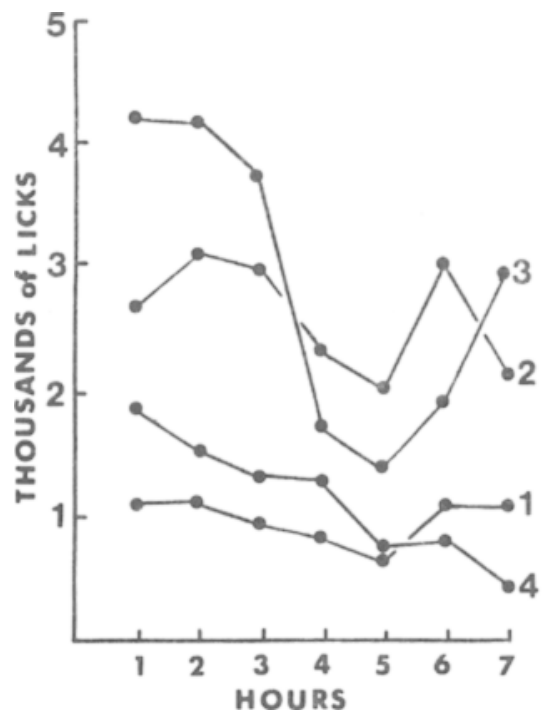

Figure 1. Numbers of licks in each experimental hour emitted by the individual subjects. number of barpresses per pellet under wet and dry conditions. Body weights and presses per pellet were virtually the same in each condition, but Subjects 2, 3 , and 4 consistently pressed faster and consumed more pellets per hour when drinking water was present than when it was absent. The deviant animal, Subject 1, was also the least prolific drinker (Table 1).

Figure 2 shows, for wet and dry conditions separately, the accumulated numbers of pellets

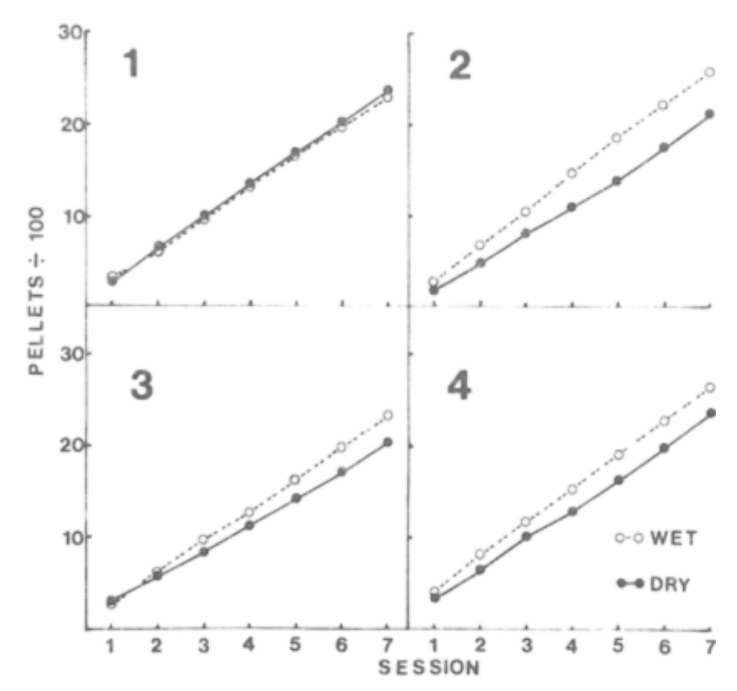

Figure 2. Session-by-session accumulation of food pellets by the individual animals under wet and dry conditions. 
obtained by each animal, session by session. The corresponding barpress records are similar in appearance, with the ordinates multiplied by the "barpresses per pellet"' factors listed in Table 2 .

Figure 3 displays mean numbers of pellets obtained in each experimental hour averaged over 6 or 7 wet and dry sessions for each animal. (Incomplete data were collected for Subjects 1, 3, and 4 on Dry Day 1 and for Subjects 2 and 3 on Wet Day 1). For the first 2 or $3 \mathrm{~h}$ under each condition, pellets were obtained at close to the maximum rate $(60 / \mathrm{h})$ but thereafter, Subject 1 again excepted, rate of pellet acquisition declined and the decline was more rapid under the dry than under the wet condition. With water, an average of $7.8 \mathrm{~g}$ of food were consumed in the last $4 \mathrm{~h}$ of experimental sessions; the comparable food intake without water was $6.3 \mathrm{~g}$. In Hour 7, the mean number of pellets consumed with water (45.1) exceeded the mean number consumed without water (29.4) at the .05 level of confidence.

The regularity of switching between eating and drinking on wet sessions is indicated in Figure 4, where the percentages of pellets followed by drinks hour by hour are shown for the individual animals. The percentages steadily declined for at least $4 \mathrm{~h}$, although, with Subjects 1 and 3, there was some later recovery. Three animals drank after more than $80 \%$ of their pellets in the first hour of the sessions; Subject 1 drank after less than $60 \%$ and did not show as much within-session decline as the other animals.

\section{DISCUSSION}

With respect to fluid intake, schedule-induced polydipsia is a maladaptive outcome of schedulecontrolled feeding. It cannot be explained as super-

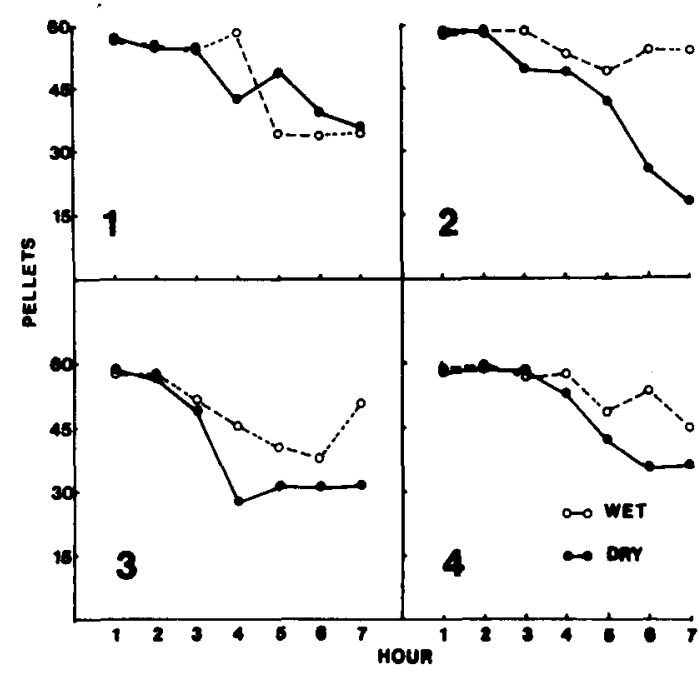

Figure 3. Mean pellets obtained per hour in wet and dry sessions by each animal.

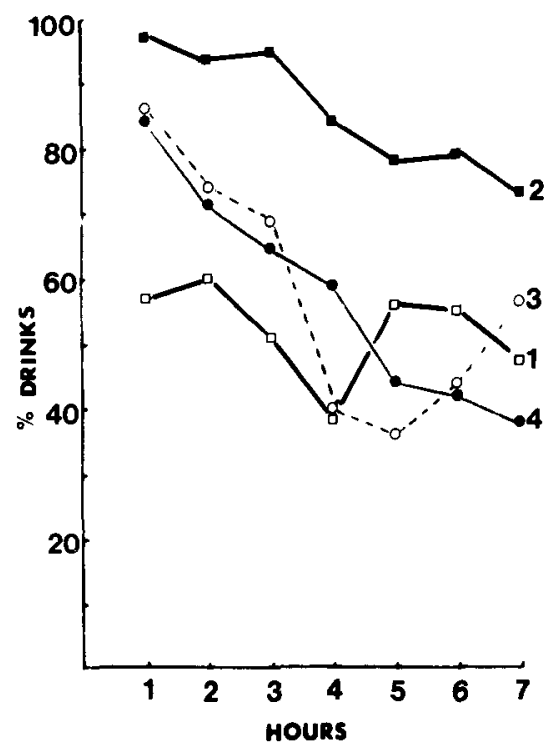

Figure 4. Percentages of pellets followed by drinks in each session hour averaged over the final six wet sessions for each animal.

stitious drinking, as postprandial drinking, as drinking energized by frustration, or as mediational drinking that expedites timing (Staddon, 1977), and it is classified with displacement, interim, and other activities that are induced by scheduled reinforcement though not specifically required for reinforcement (Falk, 1972; Staddon, 1977).

Schedule-induced polydipsia is not a particular mystery so far as the occurrence of drinking is concerned, for rats normally drink when they eat (Kissileff, 1969). What is mysterious is that eating entrains drinking to such an extent that normal physiological control of drinking does not occur. Cohen (1975) has suggested that this is because eating increases the reinforcement value of drinking water. In contrast, Keehn and Riusech (1977) have proposed that water enhances the reinforcement value of food pellets (just as sweeteners make some foods and beverages more reinforcing) and that animals driven by deprivation to eat will overdrink in satisfying their need for food. The present results bear on these proposals.

There are three things to consider about our findings: the persistence of eating, the persistence of drinking, and the relationship between them over the 7 -h sessions. As the animals were $78 \mathrm{~g}$ underweight, on the average, it is perhaps remarkable that they secured food at the maximum rate possible for only 2 or $3 \mathrm{~h}$, in which time no more than about $8 \mathrm{~g}$ of food (177 pellets) could be secured. It is unremarkable that they continued securing food, although at a reduced rate, for the remaining $4 \mathrm{~h}$ of the sessions. As the animals were not in water deficit, the persistence of drinking is notable (Falk, 1961). However, even though fluid consumption with spaced feeding con- 
siderably exceeded normal levels, drinking did not persist to the same degree as feeding, as might be expected if eating makes drinking reinforcing. All animals in the present experiment reduced their rates of licking over the first $5 \mathrm{~h}$, at least, of the 7-h sessions (Figure 1), and drinking followed a smaller proportion of the pellets consumed at the end than at the beginning of a session (Figure 4; Hymowitz \& Freed, 1972). However, the drinking that persisted until the end of wet sessions served to maintain higher levels of food consumption than occurred in dry sessions of the same length of time.

Schedule-induced drinking is apparently controlled by two opposing functions: on the one hand, it enhances eating by food-depleted animals, and on the other, it is attenuated by water satiation. Polydipsia results because the former function overrides the latter. This is maladaptive from the standpoint of fluid requirements but adaptive for underfed animals. We have argued (Keehn \& Riusech, 1977) that food plus fluid is more reinforcing than dry food alone, an argument that is supported by the present finding that barpressing for food is maintained longer when drinking is possible than when it is not. It could be claimed that the data also support the postprandial hypothesis to account for schedule-induced drinking (Lotter, Woods, \& Vaselli, 1973; Stein, 1964), but this hypothesis has been shown to be defective (Millenson, 1975; Staddon, 1977) and anyway does not explain why animals work harder for food when water is present than when it is not.

Other accounts of schedule-induced polydipsia, which assume that it exemplifies a general class of adjunctive, interim, or displacement behaviors, are offered by Falk (1977) and Staddon (1977). This assumption is weakened, however, by Heyman's (Note 1) demonstration that behavior instrumental for schedule-induced drinking obeys Herrnstein's matching law for other instrumental behavior, and by the finding of Staddon and Ayres (1975) that schedule-controlled feeding does not entrain other adjunctive behavior, like running and tunneling, as tightly as it entrains drinking. The present account of schedule-induced drinking does not assume the existence of a special class of adjunctive behaviors; it implies instead that schedule-induced drinking is governed by the normal reinforcement mechanisms that govern instrumental behavior.

\section{REFERENCE NOTE}

1. Heyman, G. The hedonic value of polydipsia for rats. Paper read at the American Psychological Association Annual Meeting, 1977.

\section{REFERENCES}

Cohen, I. L. The reinforcement value of schedule-induced drinking. Joumal of the Experimental Analysis of Behavior, $1975,23,37-44$.

Colotla, V. A., Keehn, J. D., \& Gardner, L. L. Control of schedule-induced drink durations by interpellet intervals. Psychonomic Science, 1970, 21, 137-139.

FALK, J. L. Production of polydipsia in normal rats by an intermittent food schedule. Science, 1961, 133, 195-196.

FALK, J. L. The nature and determinants of adjunctive behavior. In R. M. Gilbert \& J. D. Keehn (Eds.), Schedule effects: Drugs, drinking and aggression. Toronto: University of Toronto Press, 1972. Pp. 148-173.

FALK, J. L. The origin and functions of adjunctive behavior. Animal Learning \& Behavior, 1977, 5, 325-335.

Hawkins, T. D., Schrot, J. F., Githens, S. H., \& Everett, P. B. Schedule induced polydipsia: An analysis of water and alcohol ingestion. In R. M. Gilbert \& J. D. Keehn (Eds.), Schedule effects: Drugs, drinking and aggression. Toronto: University of Toronto Press, 1972. Pp. 95-128.

Hymowitz, N., \& FreEd, E. X. Inconstancy of drinking bursts during schedule-induced polydipsia. Psychonomic Science, 1972, 28, 283-284.

Keehn, J. D., \& Colotla, V. A. Prediction and control of schedule-induced drink durations. Psychonomic Science, 1970, 21, 147-148.

KefHn, J. D., \& Riusech, R. Schedule-induced water and saccharin polydipsia under haloperidol. Bulletin of the Psychonomic Society, 1977, 9, 413-415.

KISSILEFF, H. R. Food-associated drinking in the rat. Journal of Comparative and Physiological Psychology, 1969, 67, 284-300.

LotTer, E. C., Woods, S. C., \& VAselli, J. R. Scheduleinduced polydipsia: An artifact. Joumal of Comparative \& Physiological Psychology, 1973, 83, 478-484.

Millenson, J. R. The facts of schedule-induced polydipsia. Behavior Research Methods \& Instrumentation, 1975, 7. 257-259.

Premack, D. Reinforcement theory. In D. Levine (Ed.), Nebraska symposium on motivation. Lincoln: University of Nebraska Press, 1965. Pp. 123-180.

Staddon, J. E. R. Schedule-induced behavior. In W. K. Honig \& J. E. R. Staddon (Eds.), Operant behavior. New York: Prentice-Hall, 1977. Pp. 125-152.

Staddon, J. E. R., \& Ayres, S. L. Sequential and temporal properties of behavior induced by a schedule of periodic food delivery. Behaviour, 1975, 54, 26-49.

Stein, L. S. Excessive drinking in the rat: Superstition or thirst? Journal of Comparative \& Physiological Psychology, $1964,58,237-242$.

(Received for publication February 15, 1978; revision accepted April 17, 1978.) 